\title{
NOTAS
}

\section{De Bibliografía Indiana}

El mundo de los libros viejos, rico siempre en sorpresas, a veces las tiene mayores. Vaya un ejemplo: hace unos años, Marcel Bataillon y Dorothy Mac Mahon encontraron, cada cual por su cuenta, que las ediciones primera y segunda de la Historia peruana del contador Agustín de Zárate (Amberes, 1555 y Sevilla, 1577) diferian notablemente. Bataillon señaló que faltaban en la impresión sevillana tres importantes capitulos sobre religión incaica, ignorados en todas las impresiones modernas, ${ }^{1}$ pero citados en la época. Como si fuera poco, Jacques Cabard, halló un ejemplar de la Biblioteca Municipal de Toulouse fechado en Amberes, 1555, que aunque tenía esos capitulos suprimidos, presentaba correcciones en el libro $\mathrm{V}$ iguales a las de la reimpresión sevillana." Hubo, pues, dos tipos de primera edición, sin duda porque el cronista, presente en Flandes, quiso enmendar ciertos pliegos para él enojosos, tocantes a la rebelión contra el emperador de Gonzalo Pizarro, en la cual se vio envuelto.

Otro caso de autor indiano que altera su obra al pie de las prensas se dará un siglo después con el padre Ovalle.

\section{SOBRE LA Histórica Relación DE OVALLE}

El jesuita criollo Alonso de Ovalle, hallándose en Europa para reclutar misioneros que se aventurasen en su patria chilena, tuvo que em-

1 Dorothy Mac Mahon, prólogo a Agustin de Zárate, Historia del descubrimiento y conquista del Perti, libro V, Buenos Aires, 1955; Marcel Bataillon, "Zárate ou Lozano?" en Caravelle, Toulouse,' N2 1, 1963, pp. 11 y sigs. La Biblioteca de Autores Españole's se basa en el texto de Barcia del xvir y Barcia a su vcz en el de 1577.

2 Jacques Cabard, "Les trois transformations de la Historia de Agustín de Zárate", en Caravelle, $\mathrm{N}^{\circ} 13,1969$, pp. 7 y sigs.; otro ejemplar igual en texto al de Toulouse existe en la Biblioteca de Sainte Geneviève, Paris. 
pezar por dar a conocer su país. Publicó asi su Histórica relación del reino de Cbile (Roma, Francesco Cavalli, 1646), con abundantes láminas y un mapa; el mismo año apareció la obra en italiano, siempre por Cavalli, con muchos de los mismos grabados, ya en segunda tirada. También en 1646 y en la misma casa publicó Ovalle su propia genealogía. ${ }^{3}$ Anduvo todo el año el jesuita pendiente de esas prensas romanas, ilusionado sin duda por ver el fruto misionero que ganaría su pluma, nada despreciable por cierto.

Desde mucho, libreros y bibliófilos saben bien que es prácticamente imposible hallar un Ovalle completo: siempre faltan láminas, o bien el mapa, o alguna de las anteportadas grabadas que anteceden a los retratos de conquistadores y gobernadores chilenos; para colmo, hay que andar con tiento por si un mercader cazurro, o un poseedor inescrupuloso, no haya completado la obra con láminas provenientes de la traducción italiana, iguales pero no de ottima tiratura. Lo más difícil de obtener es una anteportada o portadilla, la cual reza Varias y curiosas noticias del reino de Chile, etc.; con ella me topé en un ejemplar sucio y falto; es tan rara que se explica el que en una moderna reimpresión de la obra, hecha en general con cuidado, no se reproduzca: ${ }^{4}$ los editores apenas mencionan la existencia de esa hoja en algunos ejemplates, pero sin transcribir su texto entero. ${ }^{5}$ Ahora bien ipuede considerarse bibliográficamente como

3 Arboles de las descencias de las muy nobles casas y apellidos de los Rodriguez del Manzano, Pastenes y Ovalles, Roma, Francisco Cavalli, 1646. Obra de un pariente, el doctor Alonso Ortiz de Ovalle (José Toribio Medina, Biblioteca Hispano-cbilena, Santiago, 1897 , vol. I, p. 458). Hay reedición, Santiago de Chile, 1922 , con prólogo y apéndice de Juan Luis Espejo.

4 Alonso de Ovalle [S. I.], Histórica relación del reino de Cbile, ed. del Insti. tuto de Literatura Chilena, Santiago, 1969; prólogo de César Bunster; la ed. se debe a Pedro Lastra, Alfonso Calderón, Julio Durán Cerda, Benjamín Rojas, Juan Durán y Carlos Santander. Para asuntos bibliográficos la base es Medina, y no se acude a Sabin o Leclerc, ni tampoco a Palau o Toda y Güell. La referencia a la portadilla se halla en apéndice (p. 490). En la ed. de José Toribio Medina, Santiago de Chile, 1888, tampoco se transcribe ese folio, cuyo texto es hoy inaccesible a la inmensa mayoría de los lectores. Anota el ilustre erudito: "En algunos ejemplares suele encontrarse una anteportada, con el título de Varias y curiosas noticias del Reino de Chile ( $\mathrm{p}$. xxvii; ver también p. xxviii).

5 Reza la portadilla: "VARIAS / Y / CVRIOSAS NOTICIAS / DEL REINO DE CHILE, / De su auẽntajado suelo, y cielo, de sus propiedades, de las de sus ha-/bitadores, del modo con que éstos, y los animales passaron de este a / aquel Nueuo mundo, de la prouabilidad de la neuegaciõ de las na-/ues de Salomon por aquellos mares por el bro, y plata, y / otras cosas para la Fabrica de / su templo./ TRATASE DEL DESCVBRIMIENTO Y PRI-/ meros Conquistadores de la América, de las Islas, y Tierra firme, / Nueua España, Nueuo Reino, Peru, Buenos Aires, Estrechos de san / Vicente, y de Magallanes, y de sus muchos puertos, y calida des;/ y vltimamente de la Conquista de Chile, de sus Gouernadores, y / primeros Capitanes, y de la porfiada guerra, y sangrientas batallas / en que desde sus principios ha campeado el valor, assi de los Espa-/ ñoles, como de los Indios, con varios sucessos, vitorias, $y$ cautiue- $/$ tios de una y otra parte, y la lastimosa 
falto un ejemplar carente de ese folio de preliminares, blanco en el verso? Para nosotros, no.

Desde José Toribio Medina hasta el Palau, los bibliógrafos advierten que es común el que un Ovalle no venga con todos sus grabados y peculiaridades. En el caso de la portadilla esquiva, se trata, creemos, de una adición tardía, hecha probablemente por el propio jesuita, para introducir novedades que mejorasen la venta. De esta necesidad hay otro claro indicio, hasta hoy ignorado.

En ese ejemplar sucio e incompleto que poseemos, comprado en Barcelona hace diez años, la portada ofrece una peculiaridad: la fecha, en vez de ser MDCXLVI, lleva dos números más, impresos pero visiblemente añadidos, para hacer MDCXIVIII. Es conocido ardid editorial, desde antiguo, el reimprimir o alterar la portada para que, al remozarse la fecha, el libro tenga mayor actualidad y mejor salida. Más tarde también llegó a nuestras manos otro ejemplar, más manchado aún que el anterior, con idéntica alteración, como para invitarnos a señalar su existencia. Se trata a todas luces de una falsa reedición.

En la moderna reimpresión chilena se ha advertido en varios lugares del texto que hay diferencia de la misma princeps; por ello los editores afirman que hay dos tipos de ejemplares (fechados claro en 1646, pues desconocen los fechados en 1648). Nos atreveríamos a decir que se quedan cortos, pues nunca cotejamos ejemplares enteramente iguales. El buen jesuita, avecindado en Roma mientras gemían las prensas de Cavalli, iba corrigiendo los pliegos mientras salian $y$, dado el antiguo modo de impresión, la cantidad de variantes que nos legó, para delicia o tormento de estudiosos, resulta sorprendente. Algo semejante al caso del cronista Zárate, o bien al más famoso de Herrera el divino en su Garcilaso con comento.

\section{LAS ARMAS DEL INCA}

Otra hoja que suele faltar: el blasón de Garcilaso Inca de la Vega en los preliminares de sus Comentarios reales, primera parte, Lisboa, 1609.

perdida de siete Ciudades, / hasta la nueua poblacion del famoso, y sinsegundo Puerto, y ciudad / de Valdiuia, y sujeción del enemigo a la Catolica Ma-/ gestad de nuestro gran Monarca Feli-/ pe Quarto. / VLTIMAMENTE SE TRATA DEL MODO CON / que se ha plantado $\mathrm{la} \mathrm{Fe}$ en aquellos Reinos, y de sus grandes pro-/ gressos, mediante los singulares fauores con que el cielo se ha mos- $/$ trado tan propicio. Representase todo esto en varias imagenes, $/$ y en el Mapa de Chile, que van puestas / en su lugar:" 
La parte segunda, en prensa a la muerte del Inca, es póstuma: Córdoba, 1617, aun cuando algunos ejemplares difieran en la portada y sean de 1616 advirtimos que esa segunda parte, o Historia general del Perú, no lleva las armas del gran escritor mestizo. Curiosamente, se entremezclan en ese blasón la mascaipacba o borla imperial incaica, la amaru o serpiente, el arco iris, el Inti -sol-, la Quilla - luna-, con "los orgullosos blasones de Vargas, Suárez de Figueroa, Saavedra y Hurtado de Mendoza", al decir de Riva-Agüero. Ese mismo escudo se halla hasta hoy en la Capilla de las Animas de la Catedral de Córdoba, tumba de Garcilaso. Algo extraño queda por aclarar, en lo cual nadie ha reparado: ¿quién le concedió al Inca aquel mixto escudo, qué rey de armas intervino para juntar a los cuarteles españoles esos símbolos gentiles? Probablemente -para nosotros, sin duda-, Garcilaso mismo, por sí y ante sí.

No es incomprensible que, muerto en Córdoba sin herederos legítimos ni reconocidos, esas armas póstumas no incomodasen a nadie. Amigo del cabildo catedralicio y de caballeros veinticuatro, el Inca vivió sus últimos años rodeado de general respeto; su nombre lo mencionan sabios andaluces como el doctor Aldrete o el jesuita Pineda, ${ }^{7}$ sin contar al abad de Rute, $^{8}$ o a Martín de Roa, ${ }^{9}$ entre otros. En la Capilla de las Animas el blasón luce harto bien, pero al frente de un libto impreso en vida, seis o siete años antes de su muerte, llama la atención. Más aún: a menos que se le hubiera autorizado el uso de aquellos emblemas incaicos, cosa de la cual ni él ni nadie da referencia, ese escudo impreso parece muy arriesgado, aun cuando la edición apareciese en Lisboa. Era quedar a merced de cualquier adversario, como al parecer lo fue el cronista real Herrera y Tordesillas.

- José de la Riva-Agüero, "Elogio del Inca Garcilaso de la Vega", en Obras completas, vol. II, Lima, 1962, p. 42. Riva-Agüero habla de llautu y no de mascdipacba, sin duda por pensar que esta era una borla tal como hoy suele entenderse; entonces consistía en un fleco, tal como hoy llamamos borla a la del birrete doctoral. Garcilaso estudió su propio linaje en su manuscrita Genealogia de Garcipérez de Vargas, hoy bien conocida.

7 José Durand, "Dos notas sobre el Inca Garcilaso", en NRFH, vol. III, No 3, 1949; sobre el escriturario Pineda y Garcilaso, Id., "El nombre de los Comentarios reales" en RMNac, Lima, vol. XXXIII, 1963, pp. 327 y sigs.; también "El influjo de Garcilaso Inca en Túpac Amaru", en Copé, Lima, vol. II, No 5, 1972, pp. 5 y sigs.

8 Para las relaciones de Garcilaso con don Francisco Fernández de Córdoba, abad de Rute, autor de Didascalia Multiplex, véase Eugenio Asensio, "Dos cartas desconocidas del Inca Garcilaso", en NRFH, 1953, vol. VII, No. 3-4.

9 El historiador y escriturario cordobés, Martín de Roa, S. I., discípulo como Pineda de Jerónimo de Prado -otro amigo del Inca-, conoció sin duda a Garcilaso, a quien evidentemente leyó, como se ve, a propósito del culto del sol, en uno de sus libros: Ecija, sus santos, su antigüedad eclesiástica y seglar, Sevilla, 1629, fo. $57 \mathrm{v}^{9}$. Sobre el Inca y el padre Roa tratamos en "El nombre de loa Comentarios reales", lor. cit. 
H I S T O R I C A

R E L A C I O N Del Reyno de C H I L E

$Y$ delas miffiones, $y$ minifterios que exercita en el la Compañia de I E S V S.

A NVESTRO SENOR

I E S V C H R I S T O

D I O S H O M B E,

$\mathrm{Y}$ ala Santifsima Virgen, y Madre

M A R I A

Señora del Cielo, y dela Tierra,

$y$ alos Santos

I O S E P H, IO A C H FN, A N A fus Padres, y Aguelos.

\section{ALONSO DE OVALLE}

Dela Compañia de IE S V S Natural de Santiago de Chile, y fu Procurador a R O M A.

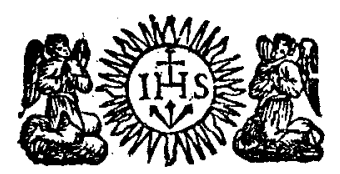

EN ROMA, por Francifco Cauallo. M. D C. XI Tyr Con licencia delos Saperiores. 
Quizás la solución se halle al mirar los bienes que dejó al morir; allí nos topamos con "Quinientos libros, poco más o menos, en papel, de la Primera parte de los Comentatios Reales". ${ }^{10}$ Impresa a costa del autor, una buena cantidad de la edición quedaba por venderse en abril de 1616. Es un hecho que dicha hoja falta hoy on muchísimos de los ejemplares existentes, al menos en la mayoría de cuantos hemos vistc. Cabe así la posibilidad, y es por demás razonable, que el blasón se añadiese en Córdoba en ese medio millar que el autor guardaba en casa. Así el blasón impreso, igual que el de su tumba, sería póstumo, honroso"11 y sin riesgos. Nuevo silencio de Garcilaso y quizás uno de sus últimos actos o secreta voluntad.

Escolio para bibliógrafos, bibliófilos y libreros: los ejemplares carentes del escudo grabado, a semejanza de los Ovalle huérfanos de la dichosa portadilla, no deben por ello considerarse incompletos. ${ }^{12}$ Se trata más bien de los más antiguos.

José Durand

The University of Michigan

10 Cf. José de la Torre y del Cerro, El Inca Garcilaso de la Vega. Nueva documentación, Madrid, 1935, p. 222.

${ }^{11}$ A la vez que se enorgullecía de su linaje, Garcilaso, como los humanistas, pensaba que la nobleza debia estribar en la virtud; lo estudiamos en "La idea de la honra en el Inca Garcilaso", en CuA., nov-dic. de 1951, pp. 194 y sigs.

12 El soberbio ejemplar del Ovalle en marroquín de época, con las armas del gran duque de Toscana, se vendia hace unos años llevando en facsímil la portadilla. Remiendo ocioso. Estando ya en prensa estas notas, llega a nuestras manos un artículo del profesor $M$. Ferreccio en el que se déscribe la portadilla del Ovalle; piensa también que se trataba de un ardid de venta. Nuestras noticias lo amplían "Presupuestos para una edición crítica de... Alonso de Ovalle", Revista Chilena de Literatura, Santiago, 2-3 (1970), pp. 2-41. 